\title{
Angiopoietin/Tek Interactions Regulate MMP-9 Expression and Retinal Neovascularization
}

\author{
Arup Das, William Fanslow, Douglas Cerretti, Erin Warren, Nicholas Talarico, and \\ Paul McGuire
}

Department of Surgery (AD, PM), Division of Ophthalmology, Cell Biology and Physiology (AD, EW, NT, PM), University of New Mexico School of Medicine, and New Mexico Veterans Health Care System (AD), Albuquerque, New Mexico; and Cancer Pharmacology Amgen Washington (WF, DC), Seattle, Washington

\begin{abstract}
SUMMARY: The objective of the study was to determine the role of the angiopoietins in the regulation of gelatinase expression during angiogenesis, and whether inhibition of the angiopoietin/Tek interaction in vivo can suppress the extent of retinal neovascularization. Retinal microvascular endothelial cells were treated with angiopoietins and examined for the production of gelatinases. The effects of inhibiting angiopoietin binding to the Tie-2 receptor was studied in newborn mice with experimentally induced retinal neovascularization. Animals were treated with an ip injection of the Tie-2 antagonist, muTek delta Fc, while oxygen-exposed mice treated with similar concentrations of murine lgG were used as controls. The effect of muTek delta Fc on the gelatinase expression in the retina was examined by real-time RT-PCR analysis. The stimulation of cultured retinal endothelial cells with Ang- 1 and -2 resulted in the increased expression of matrix metalloproteinase (MMP)-9. Ang-2 expression was up-regulated in experimental animals during the period of angiogenesis and was the greatest on Day 17 (the time of maximal angiogenic response). Histologic analysis of mice treated with the Tie-2 antagonist, muTek delta Fc, showed significant (87\%; $p=0.001$ ) inhibition of retinal neovascularization, and the response was dose-dependent. In vitro binding data support the fact that both Ang-1 and Ang-2 bind with high avidity to muTek delta Fc. The RT-PCR analysis of the retinas of the Tek-treated animals showed a similar ( $80 \% ; p=0.001)$ inhibition of the MMP-9 expression, which correlated with the decrease in angiogenesis. The up-regulation of gelatinases in microvascular endothelial cells by Ang-2 may be an important early response during the development of retinal neovascularization. Inhibition of the binding activity of the angiopoietins in vivo suppressed retinal neovascularization concomitant with a reduction in the expression of MMP-9. (Lab Invest 2003, 83:1637-1645).
\end{abstract}

$R$ etinal neovascularization is a type of pathologic angiogenesis that is associated with a number of diseases, including diabetic retinopathy, retinal vein occlusion, and retinopathy of prematurity. The new vessels in the retina are fragile and bleed easily, leading to vitreous hemorrhage and loss of vision. It is well accepted that hypoxia plays an important role in the initiation of the angiogenic process in the retina by up-regulating the production of specific growth factors. Among the growth factors involved in retinal neovascularization, vascular endothelial growth factor (VEGF) is thought to be the major mediator (Aiello, 1997). Hypoxia has been shown to up-regulate VEGF mRNA in retinal endothelial cells, pericytes, retinal pigment epithelial cells (RPE), Muller cells, and ganglion cells (Aiello et al, 1995a). In the retina, large numbers of high-affinity VEGF receptors are expressed by microvascular endothelial cells. Interaction of VEGF with these receptors leads to characteristic

\section{DOI: 10.1097/01.LAB.0000097189.79233.D8}

Received August 8, 2003.

Supported by research grant RO1 EY12604-04 (to A.D.) from the National Institutes of Health, Bethesda, Maryland.

Address reprint requests to: Dr. Arup Das, Department of Surgery, University of New Mexico School of Medicine, 2211 Lomas Boulevard, NE ACC-2, Albuquerque,New Mexico 87131.E-mail: adas@unm.edu phenotypic changes in the endothelial cells (Aiello, 1997) and subsequent regulation of specific parts of the angiogenic pathway.

In addition to the VEGF receptors, a second class of endothelial-specific tyrosine kinase receptors has been implicated in vascular growth and development. These receptors are the Tie receptors Tie-1 and Tie2/Tek (tyrosine kinase with Ig and epidermal growth factor homology domain) (Sato et al, 1993). There are four known angiopoietin ligands for the Tie receptors, Ang-1, Ang-2, Ang-3, and Ang-4. One of these ligands, Ang-2, has been shown to be selectively up-regulated by hypoxia similar to the well known growth factor VEGF.

Experiments with mouse embryos lacking in Ang-1 develop a vasculature that fails to undergo remodeling. The ultrastructural analysis of this vasculature shows that endothelial cells in these vessels fail to associate appropriately with supporting cells, which provide the Ang-1 protein that acts on endothelial Tie-2 receptors (Davis et al, 1996; Suri et al, 1996). Transgenic mice with overexpression of Ang-1 have enlarged and highly branched vessels that are resistant to VEGF-mediated leakage. Ang-1 plays a role in remodeling the developing vessels by maximizing the interactions between endothelial and supporting cells, thus promoting vessel maturation and stabilization. 
Experiments with transgenic mice overexpressing Ang-2 show a phenotype similar to Ang-1-deficient mice, demonstrating that Ang-2 probably acts as a Tie-2 antagonist (Maisonpierre et al, 1997). More recent studies also demonstrate that, depending on the context, Ang-2 may also function as a Tie-2 agonist (Teichert-Kuliszewska et al, 2001). In either case Ang-2 is postulated to provide a key destabilizing signal involved in initiating angiogenic remodeling. Destabilized vessels would be prone to regression in the absence of other growth factors; however, in the presence of VEGF, the Ang-2-stimulated capillary endothelial cells progress through the subsequent angiogenic steps (Maisonpierre et al, 1997).

A crucial step during angiogenesis is the invasion and migration of endothelial cells into and through the surrounding basement membrane and extracellular matrix. This invasive process is tightly coupled to the production and activity of specific extracellular proteinases, including the matrix metalloproteinases (MMPs) and the serine proteinase, uPA (urokinase plasminogen activator) and its receptor, uPAR (urokinase plasminogen activator receptor) (Mignatti and Rifkin, 1996; Pepper and Montesano, 1990). A balanced interplay of these proteinases and their inhibitors is implicated in the regulation of angiogenesis and has been extensively studied in tumor growth and development (Pepper and Montesano, 1990; Pepper et al, 1994; Werb et al, 1999). We have previously shown in an animal model of ischemia-induced retinal neovascularization that specific proteinases (MMP-2, MMP-9, and urokinase plasminogen activator) are upregulated in the retina of mice with experimentally induced retinal neovascularization (Das et al, 1999b). A similar up-regulation of proteinases was observed in human epiretinal neovascular membranes from patients with proliferative diabetic retinopathy (Das et al, 1999a).

Previous studies have demonstrated a major role for Ang-2 in neovascularization of the ischemic retina. The expression of Ang-2 was found to increase during the angiogenic period, as opposed to that of Ang-1 whose expression remained constant during this period (Hackett et al, 2000). In addition the Ang-2 null mouse demonstrated a significantly blunted angiogenic response in the retina compared with wild-type mice (Hackett et al, 2002). Together these data support the hypothesis that Ang-2 functions as a major promoter of vessel destabilization and retinal neovascularization in this model.

In the present study, we have examined the role of Ang-2 in the regulation of proteinase expression in retinal capillary endothelial cells and determined whether inhibition of the angiopoietin/Tek interactions in vivo could suppress the extent of retinal neovascularization in a well-established model of ischemiainduced retinopathy.

\section{Results}

\section{Expression of MMPs in Response to Ang-2}

Treatment of cultured retinal microvascular endothelial cells with increasing amounts of purified Ang-2 re- sulted in a significant increase in the level of both the pro and active form of MMP-9 secreted into the conditioned media of these cells $(p=0.01$ ) (Fig. 1, A and $\mathrm{B}$ ). This response was specific for MMP-9 because no significant increase was seen in the level of MMP-2 in response to Ang-2 stimulation (Fig. 1C). These cells also responded to stimulation with Ang-1. Incubation of cells with $100 \mathrm{ng} / \mathrm{ml}$ of Ang-1 for 18 hours increased the level of MMP-9 in the culture approximately 1.5 fold as compared with untreated cells (Fig. 2).

(A)

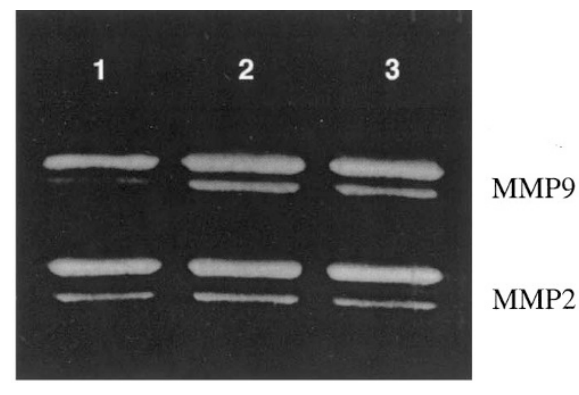

(B)
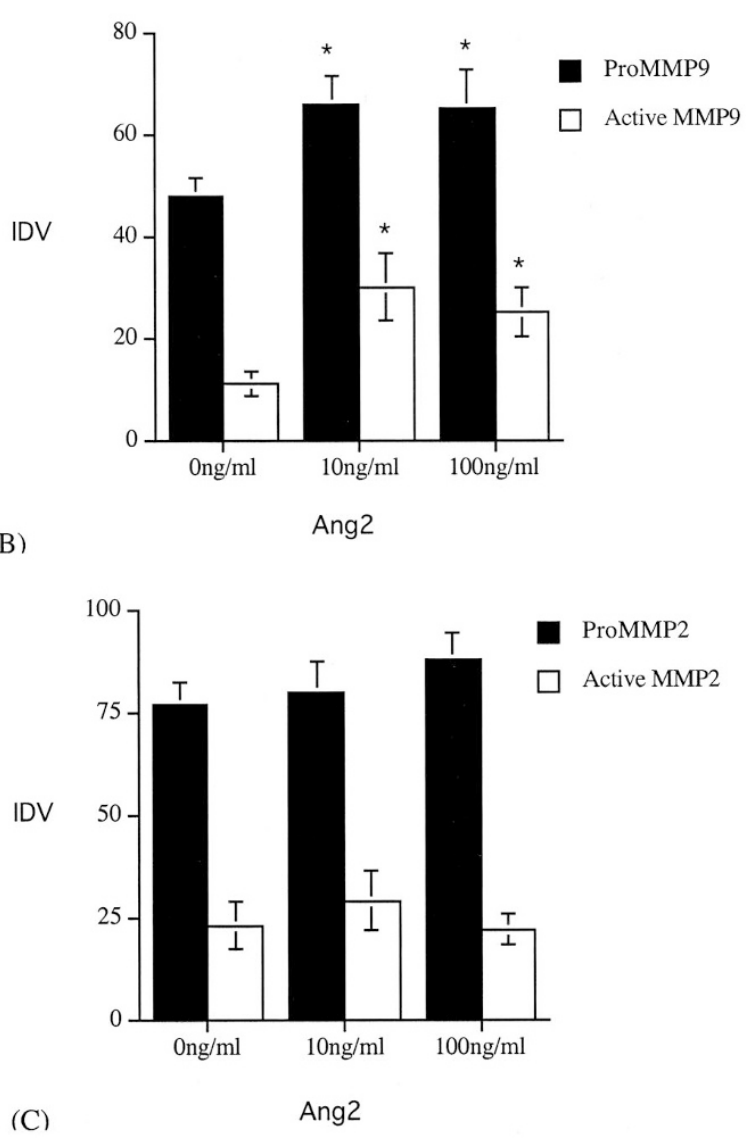

Figure 1.

(A) Representative zymography gel of matrix metalloproteinase (MMP)-2 and MMP-9 expression in cultures of retinal microvascular endothelial cells in response to Ang-2 stimulation. Lane 1, $0 \mathrm{ng} / \mathrm{ml}$ Ang-2; Lane 2, $10 \mathrm{ng} / \mathrm{ml}$ Ang-2; and Lane 3, $100 \mathrm{ng} / \mathrm{ml}$ Ang-2. Quantitation of zymography results showing MMP-9 (B) and MMP-2 (C) levels in cells treated with 0,10 , and 100 $\mathrm{ng} / \mathrm{ml}$ Ang-2 for 24 hours. *Significantly greater than untreated cells at $p<$ 0.01 . Values are the mean \pm SEM for $n=3$ separate cultures for each treatment. 


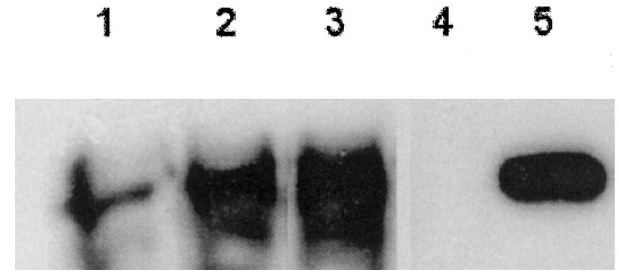

$92 \mathrm{Kda}$

\section{Figure 2.}

Western blot analysis of matrix metalloproteinase (MMP)-9 expression by retinal microvascular endothelial cells in response to Ang-1 and Ang-2 stimulation. Cells were treated with $100 \mathrm{ng} / \mathrm{ml} \mathrm{Ang-1}$ (Lane 2) or $100 \mathrm{ng} / \mathrm{ml}$ of Ang-2 (Lane 3) for 18 hours. Lane 1, no treatment; Lane 4, $10 \mathrm{ng}$ purified MMP-2 as a loading control; and Lane 5, 10 ng purified pro-MMP-9 as a loading control.

The increase in MMP-9 protein levels in response to Ang-2 stimulation correlated with an increase in the level of MMP-9 mRNA. Real-time RT-PCR analysis of MMP-9 levels in Ang-2-treated cells showed a dosedependent increase $(p=0.01)$ of mRNA production (Fig. 3).

\section{Expression of Ang-2 and MMP-9 in an Experimental Model of Retinal Neovascularization}

Real-time RT-PCR analysis of Ang-2 mRNA expression in control and experimental retinas indicated that Ang-2 expression is an important component of both normal and abnormal vessel formation. In normal room air-raised animals, Ang-2 mRNA was elevated on Days 12 and 15 when development of the normal retinal vasculature is taking place. This was followed by a significant decrease on Day 17 , which coincides

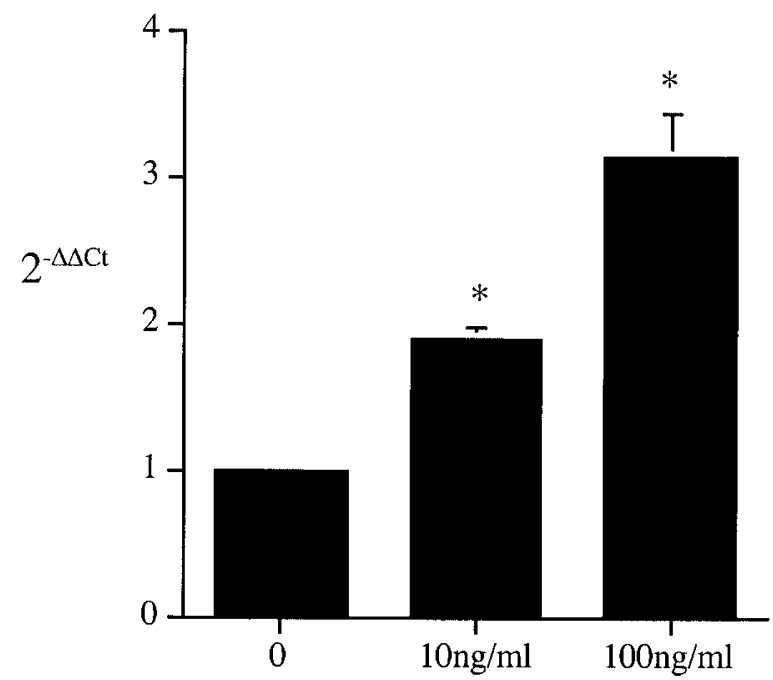

\section{Ang2 Concentration}

\section{Figure 3.}

Real-time RT-PCR analysis of matrix metalloproteinase (MMP)-9 expression in cultures of retinal microvascular endothelial cells treated with Ang-2. A significant dose-dependent increase in the level of MMP-9 mRNA was observed. *Significantly greater than untreated cells at $p<0.01$. Values are the mean \pm SEM for $n=3$ separate cultures for each treatment. with the completion of the development of the superficial retinal vascular layer $(p=0.001)$ (Fig. 4A).

In experimental animals during the development of retinal neovascularization, Ang-2 mRNA levels were significantly elevated at all ages compared with controls of the same age (Fig. 4B). A dramatic increase in Ang-2 mRNA was seen on Day 17 in experimental animals corresponding to the time of maximal retinal angiogenesis $(p=0.001)$. No changes in Ang-1 mRNA were detected in the experimental animals between Days 12 and 17 (data not shown), which agrees with previously published data (Hackett et al, 2000).

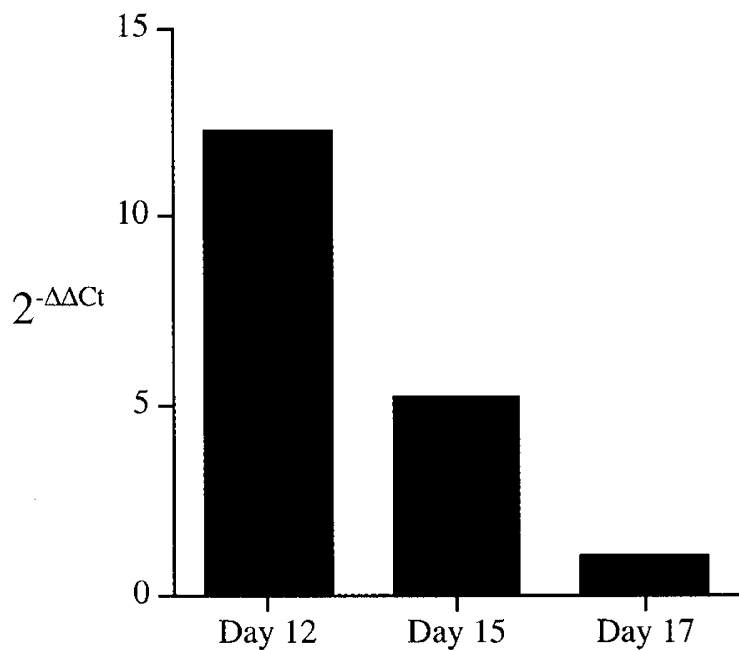

(A)

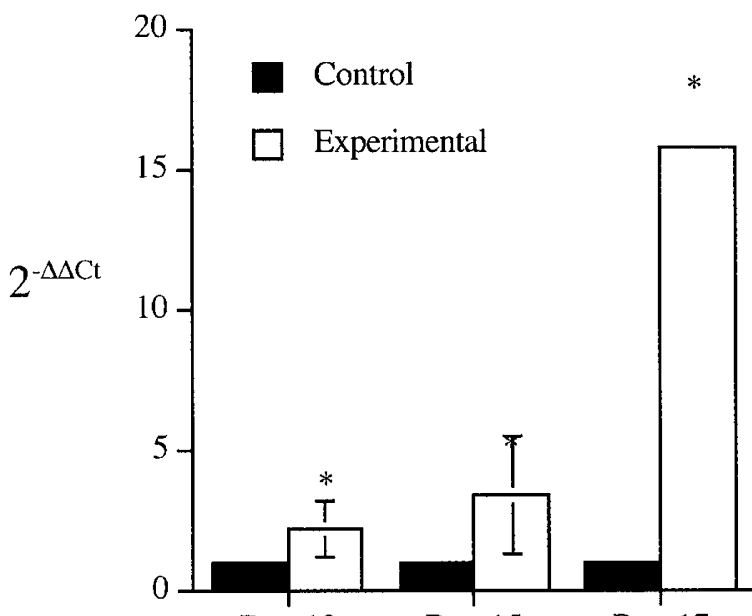

Day 12 Day $15 \quad$ Day 17

(B)

Figure 4.

(A) Real-time RT-PCR analysis of Ang-2 mRNA in the retinas from control (room air) animals on Days 12, 15, and 17. (B) Comparison of control and experimental (oxygen-treated) animals. Ang-2 is increased at all ages compared with controls, with the greatest increase seen at Day 17. Data are the mean \pm SEM of values derived using the comparative $C t$ method of triplicate reactions for $n=2$ retinas at each age. ${ }^{*}$ Significantly greater than control at $p<0.001$. 
MMP-9 expression has previously been shown to be increased in the mouse model of ischemia-induced retinal neovascularization (Das et al, 1999b). This proteinase was localized by immunohistochemical staining to the new vessels on the surface of the retina in animals with retinal neovascularization on Day 17 (Fig. 5A). Control sections incubated without the primary antibody showed no specific staining (Fig. 5B).

\section{Effect of Inhibiting the Ang-2/Tek interaction on Retinal Neovascularization}

We next examined whether inhibition of the angiopoietin/Tek interaction in the experimental mice might prevent the development of significant retinal neovascularization. The ability of muTek delta Fc (the extracellular domain of murine Tek receptor fused to the Fc portion of murine $\operatorname{lgG}$ ) to bind to murine Ang-1 and Ang-2 was determined in a plate-based solid phase binding assay. Results indicate that muTek delta Fc bound well to immobilized murine Ang-1 and murine Ang-2 compared with the control TNFR.Fc (the extracellular domain of human TNF receptor fused to the FC portion of $\operatorname{lgG}$ ), which did not show measurable binding (Fig. 6). In this assay format, the half maximal binding concentration for muTek delta Fc to murine Ang-1 was $14 \mathrm{~nm}$. The half maximal binding concentration for muTek delta Fc to murine Ang-2 was $10 \mathrm{~nm}$.

Histologic analysis of mice treated with the Tie-2/ Tek soluble antagonist, muTek-delta Fc, demonstrated a significant decrease in the numbers of capillary tufts on the vitreal side of the inner limiting membrane (Fig. 7, A and B). Quantitation of neovascular nuclei showed up to $87 \%$ inhibition of retinal neovascularization in the animal model compared with the murine IgG-treated control animals $(p=0.01)$ (Fig. $7 \mathrm{C})$. Furthermore, this response was found to be dose-dependent (46\% inhibition with $40 \mathrm{mg} / \mathrm{kg}$ Tekdelta Fc, and $87 \%$ inhibition with $80 \mathrm{mg} / \mathrm{kg}$ Tek-delta Fc treatment). Analysis of retinal sections from animals treated with increasing doses of Tek-delta Fc showed normal overall histologic structure, suggesting that there was no toxic effect of the muTek delta Fc protein on the retinal tissue. In addition, none of the treated animals showed any signs of adverse reaction to the protein therapy during the treatment period.

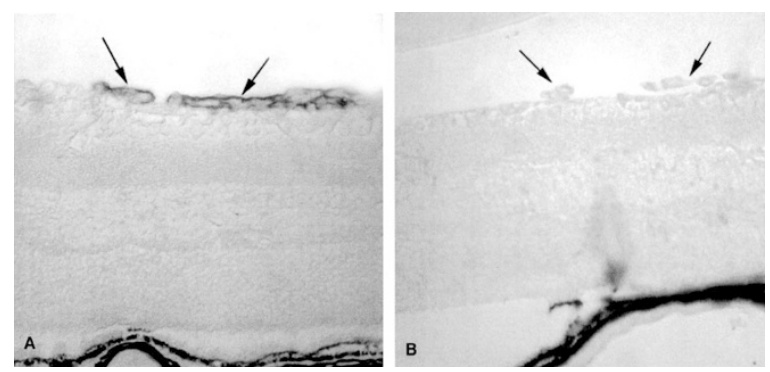

Figure 5.

Representative sections from a Day-17 experimental mouse eye stained for matrix metalloproteinase (MMP)-9. (A) Section incubated with rabbit antirat MMP-9 showing the localization of MMP-9 protein to the new vessels on the surface of the retina (arrows). (B) Control section incubated without the primary antibody. New vessels are indicated by arrows.

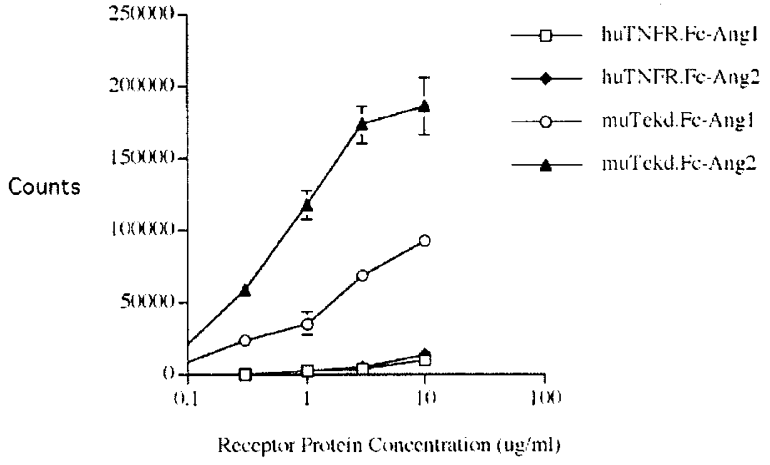

Figure 6.

Ang-1 and Ang-2 bind to murine Tek-delta Fc. Ang-1 and Ang-2 were immobilized to a 96-well plate and incubated with either murine Tek-delta Fc or human TNF receptor Fc. The degree of binding was quantitated using an antimurine Europium conjugated antibody. The data are expressed as the mean \pm SEM. The half maximal binding concentration for muTek-delta Fc to muAng-1 is $14 \mathrm{~nm}$ and to muAng-2, $10 \mathrm{~nm}$.
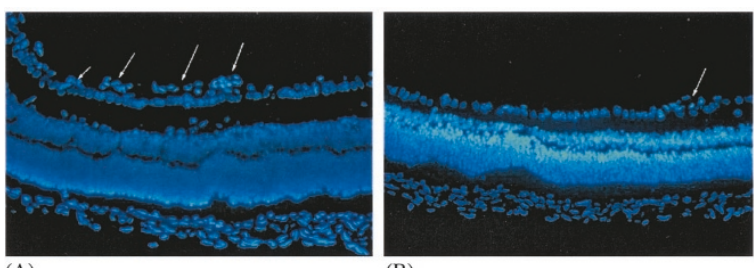

(A)

(B)

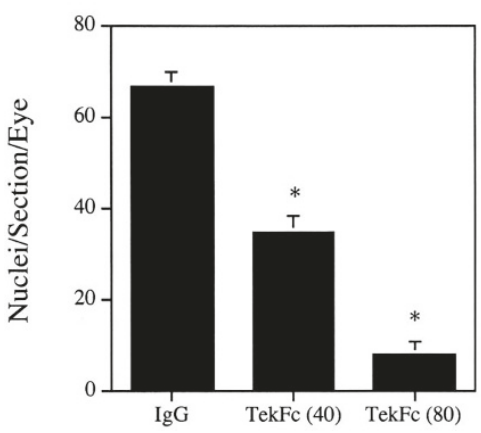

(C)

Treatment

Figure 7.

(A) Representative section of the retina from an oxygen-treated Day-17 animal receiving ip injection of $80 \mathrm{mg} / \mathrm{kg} \mathrm{IgG}$ on Days 12 to 16 . Numerous capillary tufts are seen on the vitreal side of the inner limiting membrane (arrows). (B) Representative section of the retina from an oxygen-treated Day-17 animal receiving $80 \mathrm{mg} / \mathrm{kg}$ ip injection of muTek delta Fc on Days 12 to 16 . A significant decrease in the number of capillary tufts on the vitreal side of the inner limiting membrane was observed (arrow). (C) Quantitative analysis of the extent of neovascularization in animals treated with either muTek delta Fc or $\mathrm{IgG}$. Animals treated at $40 \mathrm{mg} / \mathrm{kg}$ muTek delta Fc demonstrated up to $46 \%$ inhibition of neovascularization. In animals treated with $80 \mathrm{mg} / \mathrm{kg}$ muTek delta Fc, there was $87 \%$ inhibition of neovascularization compared with the IgG-treated animals. Values are the mean \pm SEM for $n=5$ animals (40 sections/animal) for each treatment group. *Significantly less than IgG-treated animals at the $p<0.01$ level.

\section{Effect of Inhibiting the Ang-2/Tek Interaction on Expression of MMP-g In Vivo}

In some cases the retinal tissues from IgG and muTek delta Fc-treated mice were collected and analyzed for the level of MMP-9 mRNA. Real-time RT-PCR analysis 
of the retinas from mice treated with Tek-delta Fc showed a significant (80\%) decrease in MMP-9 mRNA expression compared with the IgG-treated control animals $(p<0.01)$ (Fig. 8). muTek delta Fc treatment significantly inhibited retinal neovascularization and MMP-9 expression concomitantly. These results, together with the cell culture data, suggest that the angiopoietin/Tek interaction regulates new blood vessel formation in the retina, at least in part through the induction of MMP-9 expression.

\section{Discussion}

The biological actions of angiopoietins are mediated via specific binding interactions with Tie-2/Tek receptors expressed predominantly on the surface of endothelial cells (Maisonpierre et al, 1997). Although it was originally believed that only Ang-1 induced Tie-2/Tek tyrosine phosphorylation, recent reports have shown that Ang-2 also induces Tie-2/Tek tyrosine phosphorylation and endothelial cell survival (TeichertKuliszewska et al, 2001). The activation of Tie-2/Tek is postulated to mediate endothelial cell survival and stabilization of capillary beds via the activation of PI-3 kinase and the induction of antiapoptotic pathways in the cell (Jones et al, 1999; Kwak et al, 1999; Loughna and Sato, 2001; Maisonpierre et al, 1997). Targeted disruption of Ang-2 revealed that while Ang-2 was not required for embryonic vascular development, it was required for postnatal vessel formation and remodeling. A previous study has suggested that angiogenesis is dependent on the co-expression of both Ang-2 and VEGF (Maisonpierre et al, 1997). In the absence of VEGF, increased Ang-2 expression results in vessel regression. These data suggest a role for Ang-2 in the stimulation of angiogenesis by initial destabilization of the existing capillary bed, which in the presence of

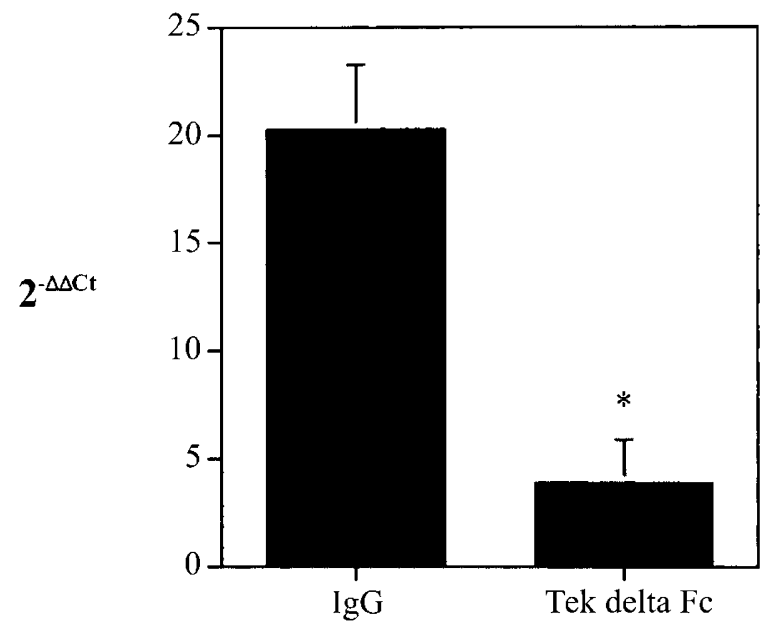

Treatment

Figure 8.

Real-time RT-PCR analysis of matrix metalloproteinase (MMP)-9 expression in the retina of IgG and muTek delta Fc-treated Day-17 animals. Data are the mean \pm SEM of values derived using the comparative $\mathrm{Ct}$ method of triplicate reactions from $n=3$ animals for each treatment group. *Significantly less than $\operatorname{IgG}$ at $p<0.01$. increased levels of VEGF will undergo the subsequent steps of new vessel formation. Other studies suggest that of the members of the angiopoietin family, Ang-2 plays the major role in pathologic retinal angiogenesis (Hackett et al, 2000, 2002). For this reason we chose to focus specifically on the effect of Ang-2 on endothelial cell gelatinase expression.

The present study used real-time RT-PCR to quantitate Ang-2 expression in the mouse retina. In the experimental mice, the level of Ang-2 was found to be increased at all stages of neovascularization and was most pronounced on Day 17 when the angiogenic response is known to be maximal. Previous studies have reported a similar finding of increased expression of Ang-2 mRNA in both the normal and ischemic mouse retina (Oh et al, 1999; Hackett et al, 2000). The in situ expression of Ang-2 was predominantly localized to cells within and near the inner nuclear layer of the retina, particularly the horizontal cells (Hackett et al, 2000). The temporal expression of Ang-2 in the retina during ischemic neovascularization is very similar to that of VEGF (Adamis et al, 1994; Aiello et al, 1994; Miller et al, 1994; Ozaki et al, 1999; Pierce et al, 1995), further suggesting that successful angiogenesis in this tissue requires the co-expression of these two growth factors.

The mechanism by which Ang-2 promotes angiogenesis was investigated by examining the role of this growth factor in the regulation of the critical step of extracellular proteinase expression. Proteolysis of the basement membrane is an important step that facilitates endothelial cell migration and subsequent tube formation (Folkman, 1982, 1986). The effect of Ang-2 on proteinase expression in cultured retinal microvascular endothelial cells was examined by both zymography and real-time RT-PCR. The results revealed a significant dose-dependent increase in MMP-9 expression by these cells. At this point it is unclear whether this is a direct stimulation of Ang-2 on MMP-9 expression resulting from signaling via the Tie-2 receptor, or whether Ang-2 is antagonizing an inhibitory activity of Ang-1, which might be present in the cell cultures.

Previous studies from this lab have demonstrated an increased expression of MMP-9 in both the mouse model of retinal neovascularization as well as in human epiretinal membranes from diabetic patients (Das et al, 1999a, 1999b; Majka et al, 2001). Further studies using proteinase inhibitors confirmed the fact that these proteinases may be appropriate targets for the development of alternative therapies in the prevention and treatment of retinal neovascularization (Das et al, 1999b). Taken together, these studies suggest that the destabilization of vessels by Ang-2 during the early events of angiogenesis may be through an upregulation of specific proteinases that alter cell/matrix interactions or the availability and/or activity of specific growth promoting factors.

Several approaches have been undertaken to therapeutically intervene in the development or progression of retinal neovascularization. These approaches 
include targeting the VEGF system (Adamis et al,1996; Aiello et al, 1995b; Robinson et al, 1996), protein kinase $\mathrm{C} \beta$ (Danis et al, 1998; Ozaki et al, 2000; Seo et al, 1999), growth hormone (Smith et al, 1997), integrins (Friedlander et al, 1996), and proteinases (Das et al, 1999b; Penn et al, 2001). The current treatment of laser photocoagulation is effective in treatment of proliferative retinopathies; however, there are significant side effects, including the loss of peripheral and night vision. In addition this treatment is not optimal because neovascularization may recur or progress requiring additional laser treatments.

The present study using an inhibitor of angiopoietin activity resulted in the suppression of retinal neovascularization by $87 \%$ at the highest dose tested ( 80 $\mathrm{mg} / \mathrm{kg}$ ). As reported in this study, the inhibitor has the ability to bind both Ang-1 and Ang-2. However, because this and other studies suggest that Ang-2 might be the more important stimulator of angiogenesis, we postulate that the inhibition of Ang-2 activity leads to the significant suppression of neovascularization. The mice showed no side effects related to the treatment, nor was there evidence of toxicity within the retinal tissues. Previous studies have employed either an im injection of an adenovirus expressing the extracellular domain of the Tek/Tie 2 receptor (Hangai et al, 2001) or an intraocular injection of a soluble Tie-2 receptor/Fc fusion protein (Takagi et al, 2003) similar to the one used in the present study. Results from these studies have demonstrated a similar although significantly lower degree of inhibition $(47 \%$ and $23 \%$, respectively) of retinal neovascularization in the same mouse model. These differences in results may reflect differences in the effective dose or concentration of protein actually presented to the retina, or differences in the binding activity or stability of the different types of proteins.

In an effort to define the mechanism by which muTek delta Fc functions, we examined changes in the expression of MMP-9 in the retinas of mice showing a positive antiangiogenic response to this compound. The inhibition of angiopoietin activity by muTek delta $\mathrm{Fc}$ in the animal model resulted in a similar (80\%) inhibition of expression of MMP-9 in these retinal tissues. This observed decrease in MMP-9 expression may be due directly to a loss of angiopoietin signaling or merely to a decrease in the number of angiogenic cells present in the retina in response to the treatment. MMP-9 and other extracellular proteinases facilitate the degradation of the basement membrane and surrounding extracellular matrix during the early stages of angiogenesis and promote the invasion and migration of capillary endothelial cells. These results suggest that the up-regulation of MMP-9 in microvascular endothelial cells by angiopoietin may be an important early response during the development of retinal neovascularization. The activity of muTek delta Fc in this model system also suggests that the stimulus for MMP-9 expression by endothelial cells in the hypoxic retina may be the up-regulation of Ang-2.
Our findings indicate that the retinal angiogenic process is mediated at least in part by the upregulation of MMP-9 due to the increased activity of Ang-2 in the tissue. Recombinant proteins such as muTek delta Fc, which specifically target activated capillary endothelial cells and reduce or suppress the expression of MMP-9, may therefore prove to be useful in the prevention or treatment of proliferative retinopathies.

\section{Materials and Methods}

\section{Cell Culture}

Bovine retinal microvascular endothelial cells were obtained from VEC Technologies (Rensselaer, New York). The cells were grown on fibronectin-coated dishes (VEC Technologies) and used at passages 3 to 5 for these experiments. The identity and purity of the cultures were confirmed by immunostaining with factor VIII antibody.

\section{Animal Model}

Specific pathogen-free C57BI/6J mice were bred at the University of New Mexico Animal Care Facility. All experiments were consistent with the Association for Research in Vision and Ophthalmology (ARVO) statement for the use of animals in ophthalmic and vision research. Seven-day-old mice and nursing mothers were placed into an oxygen chamber maintained at $75 \%$ oxygen until postnatal Day 12 . Mice were removed from the chamber on Day 12 and maintained in room air until Day 15 or Day 17. By postnatal Day 17, retinal neovascularization was present in $100 \%$ of the animals (Smith et al, 1994). Newborn mice exposed only to room air served as controls in these experiments.

\section{Gelatinase Expression}

Zymography was used to quantitate the levels and activity of MMPs produced by cultures of bovine retinal microvascular endothelial cells following treatment with Ang-2. Cells were plated onto fibronectincoated dishes and grown in media containing $0.5 \%$ fetal bovine serum overnight. The cells were subsequently grown for 24 hours in serum-free medium in the presence of 0,10 , or $100 \mathrm{ng} / \mathrm{ml}$ Ang-2 (R\&D Systems, Minneapolis, Minnesota). The conditioned media from equal numbers of cells was collected, and equal volumes were subjected to electrophoresis in $10 \%$ polyacrylamide minigels into which gelatin (1 $\mathrm{mg} / \mathrm{ml}$ ) was cross-linked. The zones of proteolysis corresponding to the presence of MMP-2 and MMP-9 were visualized by staining with $0.125 \%$ Coomassie brilliant blue. The size of the zone of clearing, which correlated with the amount of enzyme present in the sample, was quantitated using Alpha Innotech (San Leandro, California) image analysis software.

In some experiments, cells were also treated with $100 \mathrm{ng} / \mathrm{ml}$ of Ang-1 and examined by Western blotting 
for MMP-9 expression using a biotin-labeled antiMMP-9 antibody (R\&D Systems).

\section{Histological Quantitation of Retinal Neovascularization}

Control and experimental animals were killed on Day 17 , and the eyes were enucleated and fixed overnight in $10 \%$ neutral buffered formalin. Intact eyes were embedded in paraffin, and serial $6-\mu \mathrm{m}$ sections were cut parallel to the optic nerve. Sections were mounted on gelatin-coated slides and stained with GSL-FITC (Griffonia simplicifolia lectin I-fluorescein isothiocyanate) (Vector Labs, Burlingame, California) and coverslipped with a mounting medium containing diamidinophenylindole (Vector Labs). Every third section was examined with a fluorescence microscope, and nuclei belonging to GSL-positive cells on the vitreous side of the inner limiting membrane were counted. Sections containing the optic nerve were excluded because of epiretinal vasculature that might be mistaken for neovascular nuclei. The average number of neovascular nuclei per section per eye was determined. Two sample $t$ tests were done to make comparisons between experimental and control animals.

\section{muTek Delta Fc Treatment}

In some studies experimental animals were injected ip once a day from Day 12 to Day 16 with increasing doses $(40 \mathrm{mg} / \mathrm{kg}$ and $80 \mathrm{mg} / \mathrm{kg}$ ) of the fusion protein, muTek delta Fc (Amgen Washington, Seattle, Washington). The protein consists of the extracellular domain of the murine Tek receptor fused to the Fc portion of murine IgG. As a control some oxygentreated experimental animals were treated with an equivalent concentration of murine lgG rather than the muTek delta Fc. Eyes were collected at Day 17 and analyzed for the extent of retinal neovascularization as described above.

Binding of muTek delta Fc and huTek delta Fc was measured using a time-resolved fluorescence based assay. Briefly, Delphia 96-well low fluorescence plate wells (Wallac Perkin-Elmer) were coated with 50 ul per well murine Ang-1 (100 ng/ml) or murine Ang-2 at 1 ug/ml (Amgen, Inc., Thousand Oaks, California) in PBS overnight at $4^{\circ} \mathrm{C}$. After washing in PBS-Tween, the plate wells were blocked by adding 1\% BSA in PBS (100 ul/well, room temperature incubation). Standard lots of purified recombinant muTek delta Fc and huTNFR.Fc (the extracellular domain of human TNF receptor fused to the $\mathrm{Fc}$ portion of $\mathrm{lgG}$ ) were added to angiopoietin-coated wells starting at $10 \mathrm{ug} / \mathrm{ml}$ (in 1\% BSA/PBS) and titrated 3-fold in triplicate. Samplecontaining wells were incubated for 1 hour at room temperature with gentle agitation. Wells were washed with 3 volumes of PBS-Tween, and 50 ul of Delphia antimurine Europium conjugate $(100 \mathrm{ng} / \mathrm{ml})$ in Delphia assay buffer (Wallac Perkin-Elmer, Boston, Massachusetts) was added to each well and the plate incubated at room temperature for an additional 30 minutes with gentle agitation. The wells were washed with PBS-Tween and developed by addition of Del- phia enhancement solution according to manufacturer's instructions. After 5 minutes incubation at room temperature, fluorescence was measured on a Victor 2 plate reader at $615 \mathrm{~nm}$ and results reported as Europium counts.

\section{RT-PCR}

Total RNA was extracted from control and experimental retinal tissues and used to generate first strand cDNA using superscript reverse transcriptase. For real-time RT-PCR analysis, cDNA samples were analyzed using TaqMan probes and primers specific for MMP-9, Ang-2, and 18s RNA. Primers were designed using Primer Express software and purchased from Integrated DNA Technologies (Coralville, lowa). Reactions were run in triplicate, and mean values were characterized by comparing threshold cycle (Ct) values (Johnson et al, 2000). Transcripts of the 18s RNA gene were used as an endogenous control, with each unknown sample normalized to 18 s content.

\section{Immunostaining}

Retinas from Day-17 experimental animals were collected and frozen immediately in OCT compound for frozen sectioning. Sections were blocked with $10 \%$ normal goat serum and incubated with a rabbit antirat MMP-9 antibody (Chemicon, Temecula, California) at 1:300 for 60 minutes at room temperature. The sections were washed with TBS/Tween and incubated with a peroxidase-conjugated goat antirabbit antibody (Jackson ImmunResearch, West Grove, Pennsylvania) at 1:2000 for 60 minutes at room temperature. Sections were washed, incubated for 30 minutes with buffered diaminobenzidine and hydrogen peroxide, washed with water, and cover-slipped. Control sections were processed with the same protocol minus the primary antibody.

\section{References}

Adamis AP, Miller JW, Bernal MT D'Amico DJ, Folkman J, Yeo TK, and Yeo KT (1994). Increased vascular endothelial growth factor levels in the vitreous of eyes with proliferative diabetic retinopathy. Am J Ophthalmol 118:445-450.

Adamis AP, Shima DT, Tolentino MJ Gragoudas ES, Ferrara N, Folkman J, D'Amore PA, and Miller JW (1996). Inhibition of vascular endothelial growth factor prevents ischemiaassociated iris neovascularization. Arch Ophthalmol 114:6671.

Aiello LP (1997). Vascular endothelial growth factor: 20th century mechanisms, 21 st century therapies. Invest Ophthalmol Vis Sci 38:1647-1652.

Aiello LP, Avery RL, Arrigg PG, Keyt BA, Jampel HD, Shah ST, Pasquale LR, Thieme H, Iwamoto MA, Park JE, et al (1994). Vascular endothelial growth factor in ocular fluid of patients with diabetic retinopathy and other retinal disorders. N Engl J Med 331:1480-1487.

Aiello LP, Northrup JM, Keyt BA, Takagi H, and Iwamoto MA (1995a). Hypoxic regulation of vascular endothelial growth factor in retinal cells. Arch Ophthalmol 113:1538-1544. 
Aiello LP, Pierce EA, Foley ED, Takagi H, Chen H, Riddle L, Ferrara N, King GL, and Smith LE (1995b). Suppression of retinal neovascularization in vivo by inhibition of VEGF using a VEGF-receptor chimeric protein. Proc Natl Acad Sci USA 92:10457-10461.

Danis RP, Bingaman DP, Jirousek M, and Yang Y (1998). Inhibition of intraocular neovascularization caused by retinal ischemia in pigs by PKCb inhibition with LY333531. Invest Ophthalmol Vis Sci 39:171-179.

Das A, McGuire PG, Eriqat C, Ober RR, DeJuan E Jr, Williams GA, McLamore A, Biswas J, and Johnson DW (1999a). Human diabetic neovascular membranes contain high levels of urokinase and metalloproteinase enzymes. Invest Ophthalmol Vis Sci 40:809-813.

Das A, McLamore A, Song W, and McGuire PG (1999b). Retinal neovascularization is suppressed with a matrix metalloproteinase inhibitor. Arch Ophthalmol 117:498-503.

Davis S, Aldrich TH, Jones PF, Acheson A, Compton DL, Jain V, Ryan TE, Bruno J, Radziejewski C, Maisonpierre PC, and Yancopoulos GD (1996). Isolation of angiopoietin-1, a ligand for the Tie-2 receptor, by secretion-trap expression cloning. Cell 87:1161-1169.

Folkman J (1982). Angiogenesis: Initiation and control. Ann NY Acad Sci 401:212-227.

Folkman J (1986). How is blood vessel growth regulated in normal and neoplastic tissue? Cancer Res 46:467-473.

Friedlander M, Theesfeld C, and Sugita M (1996). Involvement of integrins $\alpha \mathrm{v} / \beta 3$ and $\alpha \mathrm{v} / \beta 5$ in ocular neovascular diseases. Proc Natl Acad Sci USA 93:9764-9769.

Hackett SF, Ozaki H, Strauss RW, Wahlin K, Suri C, Maisonpierre P, Yancopoulos G, and Campochiaro PA (2000). Angiopoeitin-2 expression in the retina: Upregulation during physiologic and pathologic neovascularization. J Cell Physiol 184:275-284.

Hackett SF, Wiegand S, Yancopoulos G, and Campochiaro PA (2002). Angiopoietin-2 plays an important role in retinal angiogenesis. J Cell Phys 192:182-187.

Hangai M, Moon YS, Kitaya N, Chan CK, Wu DY, Peters KG, Ryan SJ, and Hinton DR (2001). Systemically expressed soluble Tie2 inhibits intraocular neovascularization. Hum Gene Ther 12:1311-1321.

Johnson MR, Wang K, Smith JB, Heslin MJ, and Diasio RB (2000). Quantitation of dihydropyrimidine dehydrogenase expression by real-time reverse transcription polymerase chain reaction. Anal Biochem 278:175-184.

Jones N, Master Z, Jones J, Bouchard D, Gunji Y, Sasaki H, Daly R, Alitalo K, and Dumont DJ (1999). Identification of Tek/Tie2 binding partners. Binding to a multifunctional docking site mediates cell survival and migration. J Biol Chem 274:30896-30905.

Kwak HJM, So LN, Lee SJ, Kim I, and Koh GY (1999). Angiopoietin-1 is an apoptosis survival factor for endothelial cells. FEBS Lett 448:249-253.

Loughna S and Sato TN (2001). Angiopoietin and Tie signaling pathways in vascular development. Matrix Biol 20:319325.

Maisonpierre PC, Suri C, Jones PF, Bartunkova S, Wiegand SJ, Radziejewski C, Compton D, McClain J, Aldrich TH, Papadopoulos N, Daly TJ, Davis S, Sato TN, and Yancopou- los GD (1997). Angiopoietin-2, a natural antagonist for Tie-2 that disrupts in vivo angiogenesis. Science 277:55-60.

Majka SM, McGuire PG, Colombo SM, and Das A (2001). The balance between proteinases and inhibitors in a murine model of proliferative retinopathy. Invest Ophthalmol and Vis Sci 42:210-215.

Mignatti P and Rifkin DB (1996). Plasminogen activators and matrix metalloproteinases in angiogenesis. Enzyme and Protein 49:117-137.

Miller JW, Adamis AP, Shima DT, D'Amore PA, Moulton RS, O'Reilly MS, Folkman J, Dvorak HF, Brown LF, Berse B, et al (1994). Vascular endothelial growth factor/vascular permeability factor is temporally and spatially correlated with ocular angiogenesis. Am J Pathol 145:574-584.

Oh H, Takagi H, Suzuma K, Otani A, Matsumura M, and Honda $Y$ (1999). Hypoxia and vascular endothelial growth factor selectively upregulate angiopoietin-2 in bovine microvascular endothelial cells. J Biol Chem 274:15732-15739.

Ozaki H, Seo MS, Ozaki K, Yamada H, Yamada E, Okamoto N, Hofmann F, Wood JM, and Campochiaro PA (2000). Blockade of vascular endothelial growth factor receptor signaling is sufficient to completely prevent retinal neovascularization. Am J Pathol 156:697-707.

Ozaki H, Yu A, Della N, Ozaki K, Luna JD, Yamada H, Hackett SF, Okamoto N, Zack DJ, Semenza GL, and Campochiaro $P A$ (1999). Hypoxia-inducible factor-1a is increased in ischemic retina: Temporal and spatial correlation with VEGF expression. Invest Ophthalmol Vis Sci 40:182-189.

Penn JS, Rajaratnam VS, Collier RC, and Clarke AF (2001). The effect of an angiostatic steroid on neovascularization in a rat model of retinopathy of prematurity. Invest Ophthalmol Vis Sci 42:283-290.

Pepper MS and Montesano RP (1990). Proteolytic balance and capillary morphogenesis. Cell Differ Dev 32:319-327.

Pepper MS, Vassali JD, Wilks JW, Schweigerer L, Orci L, and Montesano R (1994). Modulation of microvascular endothelial cell proteolytic properties by inhibitors of angiogenesis. J Cell Biochem 55:419-434.

Pierce EA, Avery RL, Foley ED, Aiello LP, and Smith LE (1995). Vascular endothelial growth factor/vascular permeability factor expression in a mouse model of retinal neovascularization. Proc Natl Acad Sci USA 92:905-909.

Robinson GS, Pierce EA, Rook SL, Foley E, Webb R, and Smith LE (1996). Oligodeoxynucleotides inhibit retinal neovascularization in a murine model of proliferative retinopathy. Proc Natl Acad Sci USA 93:4851-4856.

Sato TN, Qin Y, Kozak CA, and Audus KL (1993). Tie-1 and Tie-2 define another class of putative receptor tyrosinase kinase genes expressed in early embryonic vascular system. Proc Natl Acad Sci USA 90:9355-9358.

Seo MS, Kwak N, Ozaki H, Yamada H, Okamoto N, Yamada E, Fabbro D, Hofmann F, Wood JM, and Campochiaro PA (1999). Dramatic inhibition of retinal and choroidal neovascularization by oral administration of a kinase inhibitor. Am J Pathol 154:1743-1753.

Smith LE, Kopchick JJ, Chen W, Knapp J, Kinose F, Daley D, Foley E, Smith RG, and Schaeffer JM (1997). Essential role of growth hormone in ischemia-induced retinal neovascularization. Science 276:1706-1709. 
Smith LE, Wesolowski E, McLellan, Kostyk SK, D'Amato R, Sullivan R, and D'Amore PA (1994). Oxygen-induced retinopathy in the mouse. Invest Ophthalmol Vis Sci 35:101-111.

Suri C, Jones PF, Patan S, Bartunkova S, Maisonpierre PC, Davis S, Sato TN, and Yancopoulos GD (1996). Requisite role of Angiopoietin-1, a ligand for the Tie-2 receptor, during embryonic angiogenesis. Cell 87:1171-1180.

Takagi H, Koyama S, Seike H, Oh H, Otani A, Matsumura M, and Honda $Y$ (2003). Potential role of the angiopoietin/Tie2 system in ischemia-induced retinal neovascularization. Invest Ophthalmol Vis Sci 44:393-402.
Teichert-Kuliszewska K, Maisonpierre PC, Jones N, Campbell Al, Master Z, Bendeck MP, Alitalo K, Dumont DJ, Yancopoulos GD, and Stewart DJ (2001). Biological action of angiopoietin-2 in a fibrin matrix model of angiogenesis is associated with activation of Tie- 2. Cardiovasc Res 49:659670.

Werb Z, Vu TH, Rinkenberger JL, and Coussens LM (1999). Matrix-degrading proteases and angiogenesis during development and tumor formation. APMIS 107:11-18. 